\title{
Retraction Note to: Novel synthesis of silver nanoparticles using Bauhinia variegata: a recent eco-friendly approach for mosquito control
}

\author{
Marimuthu Govindarajan ${ }^{1}$ - Mohan Rajeswary ${ }^{1} \cdot$ Kaliyan Veerakumar $^{1} \cdot$ Udaiyan Muthukumaran $^{1} \cdot$ S. L. Hoti ${ }^{2}$. \\ Heinz Mehlhorn ${ }^{3}$. Donald R. Barnard ${ }^{4}$. Giovanni Benelli ${ }^{5}$
}

Published online: 4 September 2021

(c) Springer-Verlag GmbH Germany, part of Springer Nature 2021

\section{Retraction Note to: Parasitol Res (2016) 115:723-733 https://doi.org/10.1007/s00436-015-4794-3}

The Editors-in-Chief have retracted this article. Concerns were raised regarding a number of images, specifically:

- Fig. 5 appears to overlap with Fig. 6 of (Govindarajan and Benelli 2016)

- Fig. 6 appears to be identical to Fig. 3 of (Govindarajan and Benelli 2016)

Additionally, the article shows significant overlap with a number of previously published articles (Muthukumaran et al. 2015a, b, c).

S.L. Hoti, Heinz Mehlhorn and Giovanni Benelli agree to this retraction. Marimuthu Govindarajan, Mohan Rajeswary, Kaliyan Veerakumar, and Donald R. Barnard haven't

The original article can be found online at https://doi.org/10.1007/ s00436-015-4794-3.

Marimuthu Govindarajan

drgovindzoo@yahoo.com

$\triangle$ Giovanni Benelli

benelli.giovanni@gmail.com

1 Unit of Vector Control, Phytochemistry and Nanotechnology, Department of Zoology, Annamalai University, Annamalai Nagar 608 002, Tamil Nadu, India

2 Regional Medical Research Centre, Nehru Nagar, Belgaum 590010, Karnataka, India

3 Department of Parasitology, Heinrich Heine University, Düsseldorf, Germany

4 Center for Medical, Agricultural, and Veterinary Entomology, USDA-ARS, 1600 SW23rd Drive, Gainesville, FL 32608, USA

5 Department of Agriculture, Food and Environment, University of Pisa, via del Borghetto 80, 56124 Pisa, Italy responded to correspondence regarding this retraction. The editor was not able to obtain a current email address for Udaiyan Muthukumaran.

\section{References}

Govindarajan M, Benelli G (2016) Facile biosynthesis of silver nanoparticles using Barleria cristata: mosquitocidal potential and biotoxicity on three non-target aquatic organisms. Parasitol Res 115:925-935. https://doi.org/10.1007/s00436-015-4817-0

Muthukumaran U, Govindarajan M, Rajeswary M (2015a) Green synthesis of silver nanoparticles from Cassia roxburghii-a most potent power for mosquito control. Parasitol Res 114:4385-4395. https://doi.org/10.1007/s00436-015-4677-7

Muthukumaran U, Govindarajan M, Rajeswary M (2015b) Mosquito larvicidal potential of silver nanoparticles synthesized using Chomelia asiatica (Rubiaceae) against Anopheles stephensi, Aedes aegypti, and Culex quinquefasciatus (Diptera: Culicidae). Parasitol Res 114:989-999. https://doi.org/10.1007/ s00436-014-4265-2

Muthukumaran U, Govindarajan M, Rajeswary M et al (2015c) Synthesis and characterization of silver nanoparticles using Gmelina asiatica leaf extract against filariasis, dengue, and malaria vector mosquitoes. Parasitol Res 114:1817-1827. https://doi.org/10. 1007/s00436-015-4368-4

Publisher's note Springer Nature remains neutral with regard to jurisdictional claims in published maps and institutional affiliations. 